\title{
A comparison between a new vitrification protocol and the slow freezing method in the cryopreservation of prepubertal testicular tissue
}

Moacir R.M. Radaelli1,2,3, Carlos G. Almodin ${ }^{3}$, Vânia C. Minguetti-Câmara ${ }^{3}$, Paula Motta Almodin Cerialli³, Aissar E. Nassifi ${ }^{1}$, Antonio J. Gonçalves ${ }^{2}$

${ }^{1}$ Urology Department, Medical School, Faculdade Ingá, Maringá, Brazil.

2 Surgery Department, Santa Casa de São Paulo Medical Sciences School, São Paulo, Brazil.

3 Materbaby - Human Reproduction and Genetics Clinic, Maringá - 87.013-230, Brazil.

\section{ABSTRACT}

Objective: This study aimed to compare a new vitrification protocol with reduced cryoprotectant exposure to the slow freezing method in the cryopreservation of prepubertal rat testicular tissue.

Methods: Five sexually immature male Wistar rats were submitted to bilateral orchiectomy. Tissue samples from each testicle were fragmented into small pieces and randomly assigned to three groups: Group $A$, fresh tissue (control); Group B, slow programmable freezing (SPF); and Group C (vitrification). Frozen/thawed, vitrified/warmed, and fresh testicular tissue were histologically compared. A pathologist blinded to the procedures assessed the morphology (cell differentiation, nuclei, and epithelium) of 10 seminiferous tubules from each testicle (100 tubules per Group).

Results: Sertoli and spermatogonial stem cells were easily differentiated, and the nucleoli were easily viewed in the tubules assessed in all three groups. Small alterations in tissue architecture were observed in the control group as a result of tissue handling. Moderate alterations of the epithelium with the formation of small gaps and cell detachment from the basement membrane were observed in $28 \%$ of the frozen and $9 \%$ of the vitrified tubules. Condensed nuclei involving a small proportion of cells were observed in six and three tubules of the frozen and vitrified group, respectively. Despite the alterations, $97 \%$ of the frozen and $99 \%$ of the vitrified tubules were considered well preserved.

Conclusions: The findings indicate that the vitrification protocol tested in this study adequately preserved the morphological integrity of prepubertal testicular tissue in a rat model. Further studies are required to confirm testicular tissue function after grafting.

Keywords: Cryopreservation, testicle, rat, cell, vitrification

\section{INTRODUCTION}

In recent decades, many patients have benefited from early diagnosis and improved efficacy of cancer treatments. Increased cure rates and longer survival, once thought to be impossible, are now becoming more common in different types of cancer. Survival rates have risen due to enhanced treatment effectiveness and improved sideeffect management, particularly in children (Ries et al., 2004; Steliarova-Foucher et al., 2004). Cure rates among pediatric cancer patients may be as high as $80 \%$ (Aslam et al., 2000; Brenner et al., 2007). It was estimated that in 2010 for every 250 adults there would be one survivor of pediatric cancer (Bleyer, 1990; Blatt, 1999).

More recently, researchers have been turning their heads to the deleterious effects of cancer treatment. A concern has been the damage to testicular germ cells, also known as gonadal toxicity, and the potential ensuing temporary or permanent infertility (Howell \& Shalet, 1998;
Brougham et al., 2003; Wallace et al., 2005). A large number of patients remain infertile after cancer treatment, and $30 \%$ are diagnosed with definitive azoospermia, i.e., absence of sperm in the ejaculate (Schrader et al., 2001). Loss of fertility may occur in up to $90 \%$ of the cases, depending on the type of disease, treatment or combination of treatments, number of cycles, and pretreatment fertility and hormonal levels (Trottmann et al., 2007; Romerius et al., 2011). An example is the situation faced by young boys with acute leukemia undergoing chemotherapy and total body radiation, $85 \%$ of whom progress to definitive azoospermia (Anserini et al., 2002).

Thus, despite the progress seen in cancer treatment and the growing number of cured children, associated gonadal toxicity has led to increased adult infertility (Ries et al., 2004; Steliarova-Foucher et al., 2004; Magnani et al., 2006; Stiller et al., 2006). In the age groups in which spermatogenesis is complete, cryopreservation of semen is well established as a method to preserve fertility (Di Santo et al., 2012). However, since spermatogenesis is not present in pediatric groups, no reliable technique for the preservation of fertility of prepubertal males is yet available (Levine et al., 2010). In this particular age group, harvesting and cryopreserving immature germinal tissue for later transplantation may be the only option for the preservation of fertility.

The functional architecture of testicular germinal tissue illustrates a case of clear intercellular dependency, with Sertoli cells playing a key role in the differentiation of spermatogonial stem cells (SSCs) into spermatozoa. Thus, in order to preserve the maturation capability of SSCs, all groups of tubular cells present in the prepubertal testicular tissue must be adequately cryopreserved (Ogawa et al., 2005). However, the cells that make up the testicular tissue structure differ in size and metabolism, which represents a challenge for cryopreservation protocols (Keros et al., 2005).

The cryopreservation of testicular tissue has been attempted through slow freezing or vitrification. Slow programmable freezing (SPF) has been considered the first choice for the cryopreservation of testicular tissue. Several studies have already demonstrated that SPF can effectively freeze and adequately preserve testicular tissue morphological integrity (Keros et al., 2005; Kvist et al., 2006; Wyns et al., 2007; Milazzo et al., 2008). However, $\mathrm{SPF}$ is a time consuming procedure that demands complex and costly equipment only found in large urban centers, possibly delaying the start of cancer therapy.

Vitrification is a relatively new, simple and cost-effective cryopreservation method that has been increasingly used in the cryopreservation of cells and tissues as an alternative to SPF (Neri et al., 2004, Almodin et al., 2010). Several animal (Curaba et al., 2011; Gouk et al., 2011; Baert et al., 2012; Poels et al., 2012; Liu et al., 2013) and human (Curaba et al., 2011; Baert et al., 2013; Poels et al., 2013; Sá et al., 2012) studies have recently used 
vitrification in the cryopreservation of prepubertal testicular tissue with encouraging results. These studies have shown that the preservation of testicular cells and tissue through vitrification has been at least as effective as traditional slow freezing protocols (Curaba et al., 2011; Baert et al., 2012; 2013; Sá et al., 2012). Despite the encouraging results, the search for an optimal cryopreservation protocol capable of successfully and predictably restoring fertility to prepubertal males is still ongoing (Baert et al., 2013).

Therefore, in order to further the investigation on the use of vitrification as a viable alternative for the cryopreservation of immature testicular tissue, this study aimed to compare a new vitrification protocol with reduced cryoprotectant exposure time devised to preserve the morphological integrity of prepubertal testicular tissue in rats to a traditional slow programmable freezing (SPF) protocol.

\section{MATERIALS AND METHODS}

The Ethics Committee for Research Involving Animals at the Santa Casa de São Paulo Medical Science School approved this study (permit $n^{\circ}$. 014/11). Surgical procedures were carried out at the Animal Surgery Center of the Ingá University Center (UNINGÁ) in the city of Maringá, Brazil, between February 2011 and July 2012, according to the guidelines established by the Brazilian College of Animal Experimentation (COBEA).

\section{Sample characterization}

The study included five sexually immature male Wistar rats (Rattus norvegicus albinus, Rodentia Mammalia), obtained from the State University of Maringá Central Vivarium. The animals were carefully screened for signs of physical anomalies such as ill-formed testes, tumors, cryptorchidism and monorchism. The animals selected were aged between 13 and 30 days and weighed between 150 and 180 grams.

\section{Study design}

A total of 10 testicles were used in this experiment. Each testicle was fragmented into three equal parts and randomly allocated into three groups: Group A (control group) - after decapsulation, the fresh testicular tissue specimens were placed in a flask containing $10 \%$ formaldehyde and immediately sent to the laboratory for processing; Group B - testicular tissue specimens were cryopreserved through slow programmable freezing; and Group C - testicular tissue specimens were vitrified according to a previously described protocol (Almodin et al., 2010). The cryopreserved testicular tissue fragments were stored into liquid nitrogen for a month. The vitrified/ warmed and frozen/thawed tissue were processed and histologically assessed in the same fashion as the fresh tissue specimens. The primary endpoint was preservation of prepubertal tissue morphology after cryopreservation.

\section{Surgical procedures}

General anesthesia was induced by an intraperitoneal injection of a solution containing $2 \%$ xylazine hydrochloride $10 \mathrm{mg} / \mathrm{kg}$, and $10 \%$ ketamine hydrochloride $75 \mathrm{mg} / \mathrm{kg}$ (Bayer Animal Health, São Paulo, Brazil). The testes of the animals were surgically removed, placed into cold saline solution at $4^{\circ} \mathrm{C}$ and sent to the laboratory. At the end of surgery, the animals were euthanized with an overdose of anesthetics.

\section{Tissue preparation}

In the laboratory, the testes were promptly washed in cold $\left(4^{\circ} \mathrm{C}\right)$ Dulbecco's phosphate-buffered saline solution (GIBCO, cat. 14040-133), and the tunica albuginea was sectioned to expose the seminiferous tubules. The tunica albuginea was completely removed and discarded, and the intra-testicular tissue remaining on the dish was sectioned into fragments of approximately $2-3 \mathrm{~mm}^{2}$. To avoid tissue loss due to temperature increases, cold buffered solution was added to the dish whenever necessary. The fragmented testicular tissue on the dish was visually separated into three equal parts and randomly allocated to the three experimental groups (Figure 1). Total time from the surgical removal of the testes to the start of the cryopreservation procedure was approximately $5 \mathrm{~min}$.

\section{Slow programmable freezing (SPF)}

The seminiferous tubules allocated to Group B were placed in $1.8 \mathrm{ml}$ cryovials (Corning, USA) containing 1.5 $\mathrm{ml}$ of cryoprotectant medium (DMSO $1.0 \mathrm{M}$, sucrose 0.05 $\mathrm{M}$ and physiological saline $10 \%$ ) at $4^{\circ} \mathrm{C}$ for $30 \mathrm{~min}$. The cryovials were then placed in a programmable freezer (Biocool) with the following freezing curve: from $5^{\circ} \mathrm{C}$ to $-9^{\circ} \mathrm{C}$, at a $2^{\circ} \mathrm{C} / \mathrm{min}$ rate, when manual seeding was induced for ice crystal nucleation, followed by a new cooling rate of $0.3^{\circ} \mathrm{C} / \mathrm{min}$ to $-40^{\circ} \mathrm{C}$. After freezing, the cryovials were plunged into a liquid nitrogen tank, where they stayed for a month.

Thawing was performed by removing the tissue from the cryovials and rapidly warming the specimens to $37^{\circ} \mathrm{C}$ by consecutively placing them for $5 \mathrm{~min}$ in each of the following solutions: i) DMSO $1.0 \mathrm{M}$, sucrose $0.05 \mathrm{M}$ and physiological saline $10 \%$; ii) DMSO $0.5 \mathrm{M}$, sucrose 0.05 $\mathrm{M}$ and physiological saline $10 \%$; iii) sucrose $0.05 \mathrm{M}$ and physiological saline $10 \%$; and iv) buffered medium and physiological saline $10 \%$. Then the samples were placed in formaldehyde $10 \%$ and sent to histological processing.

\section{Vitrification}

In Group C, the seminiferous tubules were transferred to a cryovial containing equilibrium solution (VI-1-Ingamed, Maringá, Brazil) with $7.5 \%$ ethylene glycol and $7.5 \%$ dimethyl sulfoxide (DMSO) for $10 \mathrm{~min}$ at $4^{\circ} \mathrm{C}$. Then the samples were transferred to a vitrification solution (VI-2 Ingamed, Maringá, Brazil) with $15 \%$ ethylene glycol, $15 \%$ DMSO, and sucrose $0.5 \mathrm{M}$ for $2 \mathrm{~min}$ at $4^{\circ} \mathrm{C}$. Total exposure time to cryoprotectant media was around $12 \mathrm{~min}$. With the aid of tweezers, the testicular tissue fragments were placed in cryovials containing liquid nitrogen. The cryovials were then closed and transferred to a liquid nitrogen storage tank. Whenever the tissue was transferred from one solution to the next, and before immersion into liquid nitrogen, excess solution was removed by placing the tissue specimen on dry sterile gauze. Figure 2 illustrates the different vitrification steps.

A month later, the cryovials were removed from the storage tank and the tissue specimens were immediately transferred to a warming solution (DV-I - Ingámed, Maringá, Brazil) containing sucrose $1 \mathrm{M}$ at $37^{\circ} \mathrm{C}$ for 1 min. The specimens were then transferred to a diluting solution (DV-II - Ingamed, Maringá, Brazil) containing $0.5 \mathrm{M}$ sucrose, and washed in a buffered solution (DVIII - Ingámed, Maringá, Brazil) for 5 min each. Once the testicular tissue specimens had been completely warmed, samples from each tests were placed in $10 \%$ formaldehyde and sent to histological processing.

\section{Histological analysis}

All testicular tissue samples were coded so that the pathologist responsible for the histological analysis was blinded to the groups. Each tissue specimen was dehydrated with ethanol, embedded in paraffin, and cut into $4 \mu \mathrm{m}$ serial slices with a minimal interval of $20 \mu \mathrm{m}$ between cuts. Two slides per sample were prepared, stained with hematoxylin-eosin, and analyzed on an optical 


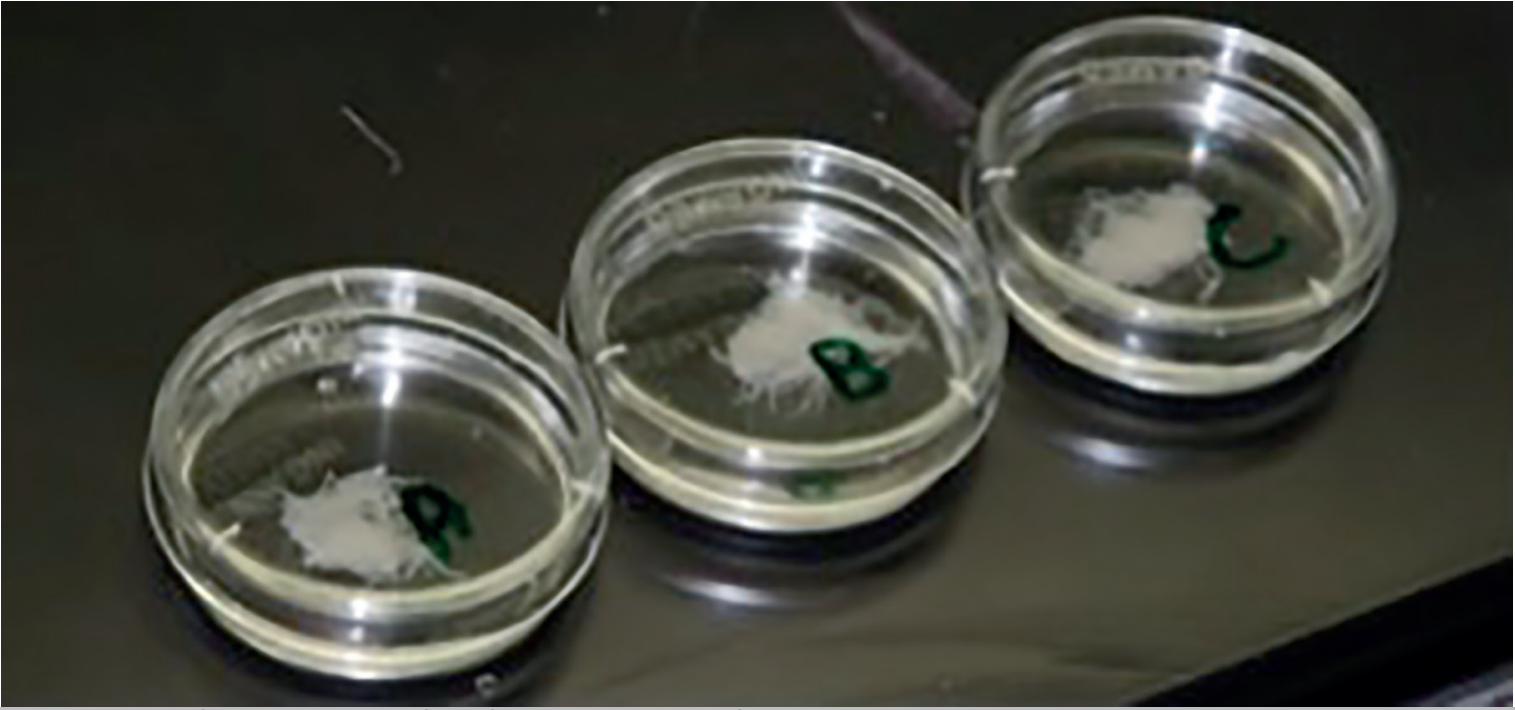

Figure 1. Fragmented tissue assigned to three experimental groups.

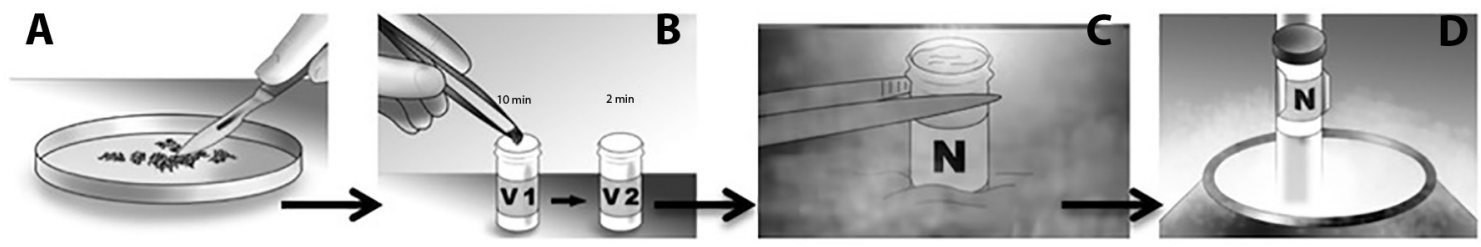

Figure 2. Vitrification scheme: A - Fragmentation of testicular tissue; B - Immersion in solution VI-1 for 10 minutes and transfer to solution VI-2; C - Tissue removed from solution VI-2 and immersed directly in liquid nitrogen; Cryovial with tissue being immersed in liquid nitrogen to be stored in a nitrogen tank.

microscope (Olympus BX Series), magnification 100X. Ten seminiferous tubules per testicle were analyzed.

Morphological integrity and structural changes to the seminiferous tubules of fresh controls and cryopreserved and thawed sections were defined based on tissue architecture (cell differentiation and tubular alterations), as follows.

- Cell differentiation (spermatogonia and Sertoli cells): I) Differentiation of Sertoli from spermatogonial cells was categorized as easy, difficult, or impossible; II) Nucleoli were either easily observed (visible in $>40 \%$ of cells) or indistinguishable (in case of many highly condensed pyknotic nuclei); iii) Presence or absence of nuclei condensation.

- Tubular epithelium (constituted by intratubular cells) alterations: I) If cell detachment from the basement membrane was absent, partial, or total ( $>75 \%$ of the circumference); ii) If gap formation and shrinkage were absent, slightly present, or obviously present.

\section{RESULTS}

The animals selected for the experiment had healthy testes of adequate shape and size.

\section{Group A (fresh tissue)}

Approximately $92 \%$ of the seminiferous tubules in fresh tissue specimens were structurally normal. The remaining $8 \%$ had slight alterations but the morphology was considered to be good (both epithelium and nuclei). Cells could be easily differentiated and no nucleus condensation was observed in the analyzed tubules. Alterations were observed in the architecture of fresh tissue specimens with the formation of gaps between tubular cells (Figure 3 ). Many of these changes probably resulted from hypoxia and handling during the preparation of the material and before fixation.

\section{Group B (frozen/thawed tissue)}

The morphology of frozen/thawed and fresh testicular tissue specimens was generally similar. In this group, approximately $62 \%$ of the tubules were undamaged, and $97 \%$ were well preserved. The main damages included moderate alterations of the epithelium with the formation of small gaps and cell detachment from the basement membrane, as seen in $28 \%$ of the examined tubules. Condensed nuclei involving a small portion of cells (less than $20 \%$ ) were observed in six tubules (Figure 4 ).

\section{Group C (vitrified/warmed tissue)}

Vitrified/warmed and fresh tissue specimens also shared a similar morphology. Approximately $79 \%$ of the tubules in this group were undamaged, and $99 \%$ were considered well preserved. Slight alterations of the epithelium with the formation of small gaps and cell detachment from the basement membrane were seen in nine of the 100 tubules examined. Nucleus condensation involving less than $10 \%$ of the nuclei was seen in three tubules (Figures 5 and 6 ).

Overall, the nuclei were well preserved and Sertoli cells (small ovoid nuclei arranged perpendicularly to the basement membrane), spermatogonia, and spermatocytes 


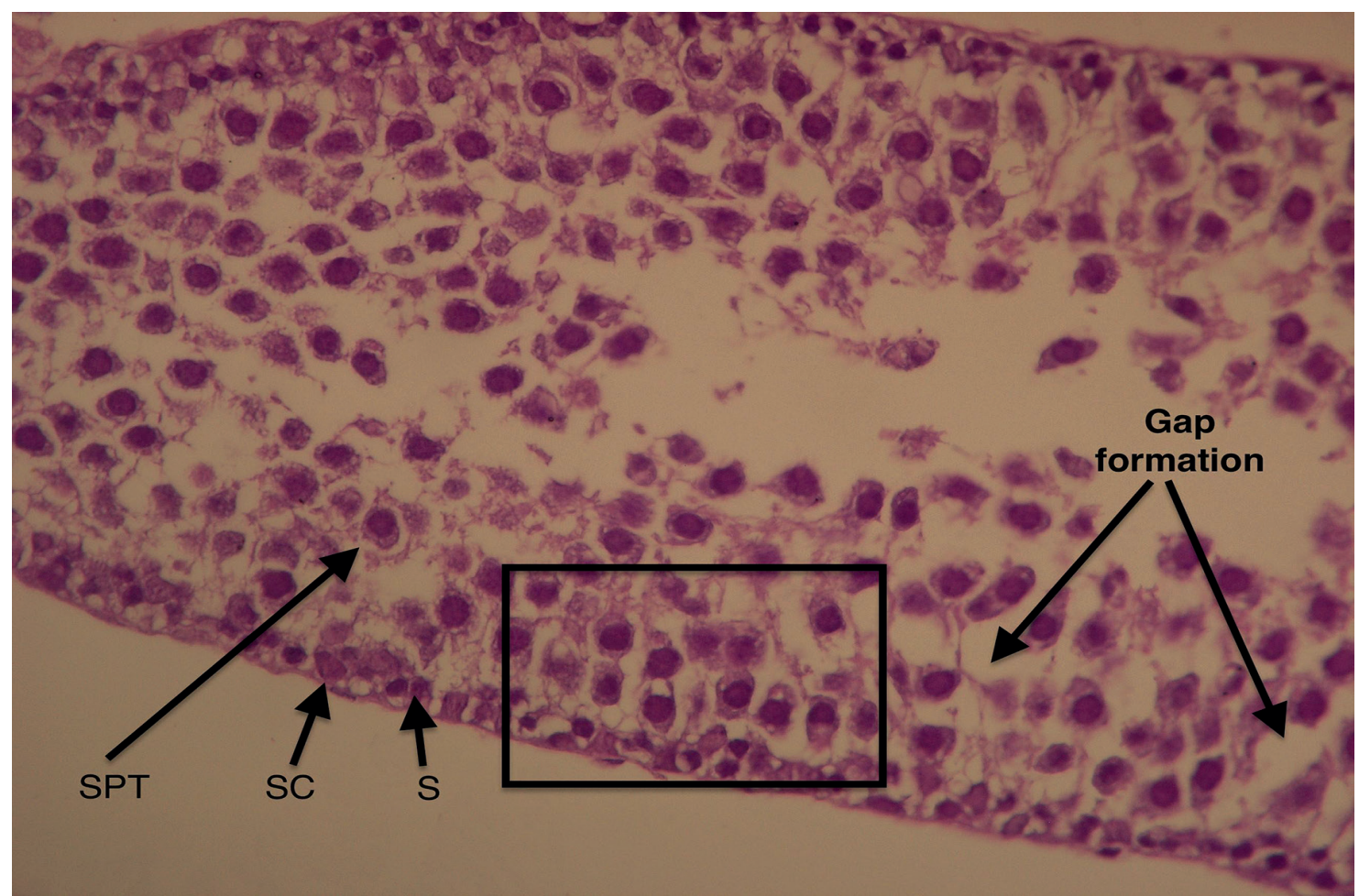

Figure 3. Longitudinal section of a fresh testicular tubule (Group A). The different cells that make up the tubular architecture can be easily made. SC: Sertoli cells; S: spermatogonia cells; SPT: spermatocytes. Formation of intercellular gaps (arrows). See the preservation of tissue architecture in the square (intercellular relation). Magnification 100X.

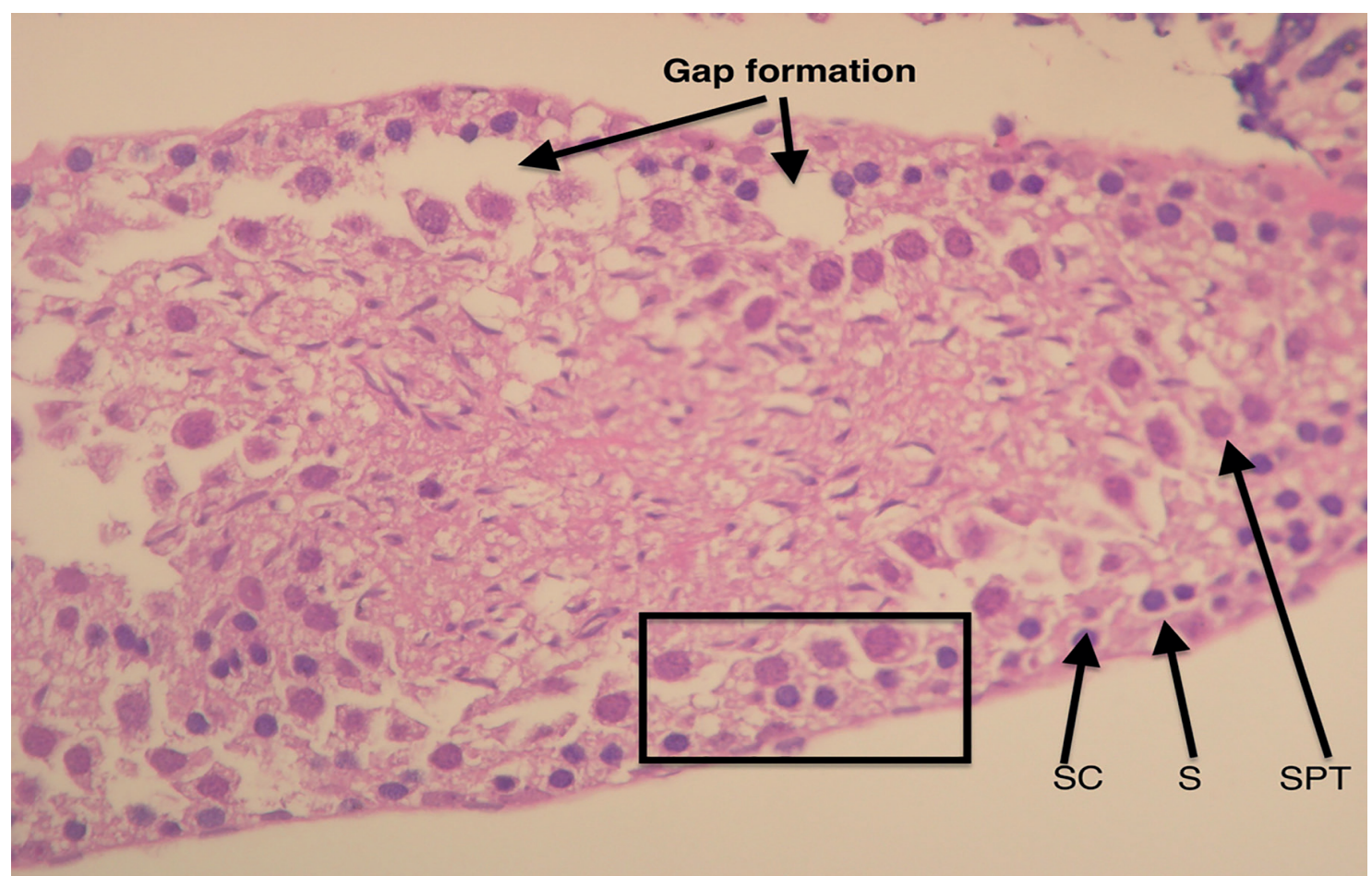

Figure 4. Longitudinal section of a frozen/thawed testicular tubule (Group B). The different cells that make up the tubular architecture can be easily made. SC: Sertoli cells; S: spermatogonia cells; SPT: spermatocytes. Formation of intercellular gaps (arrows). See the preservation of tissue architecture in the square (intercellular relation). Magnification 100X. 


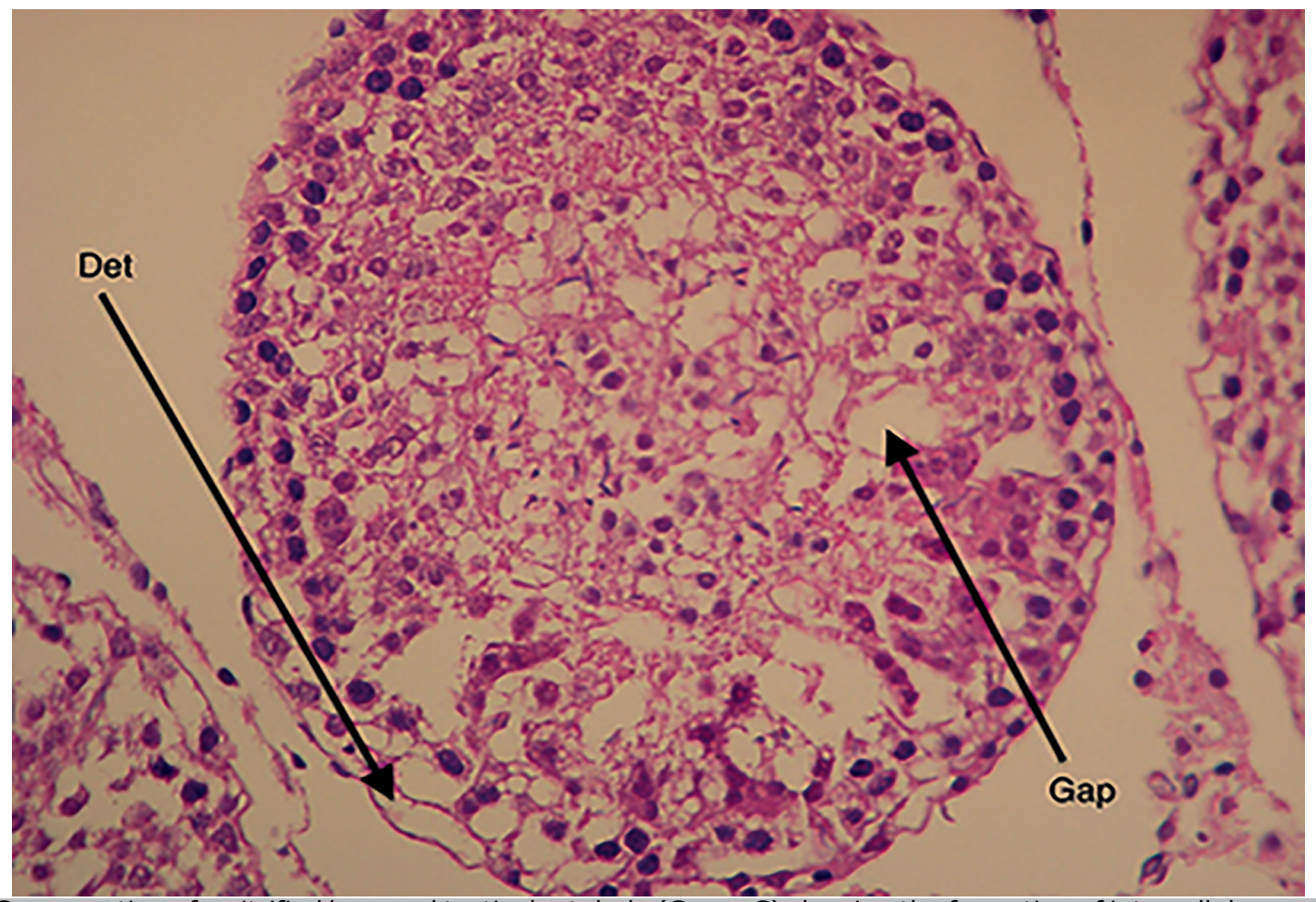

Figure 5. Cross-section of a vitrified/warmed testicular tubule (Group C) showing the formation of intercellular gaps (arrows). Det: detachment from the basement membrane. Magnification 100X.

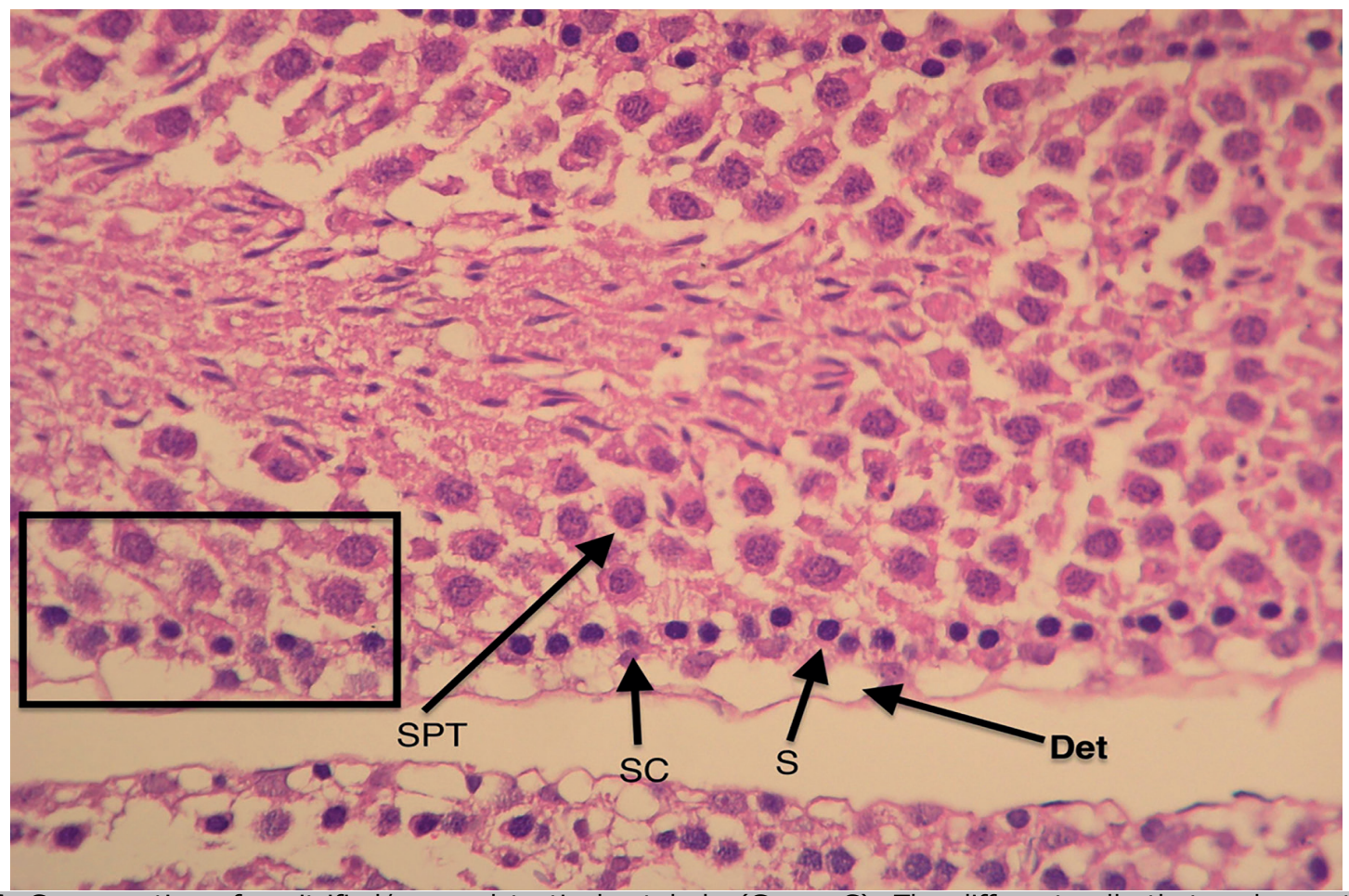

Figure 6. Cross-section of a vitrified/warmed testicular tubule (Group C). The different cells that make up the tubular architecture can be easily made. SC: Sertoli cells; S: spermatogonia cells; SPT; spermatocytes; Det: detachment from the basement membrane. See the preservation of tissue architecture in the square (intercellular relation). Magnification 100X. 
(maturing cells with large spherical nuclei) could be easily differentiated in the testicular tissue specimens of the three study groups. Cryopreserved tissue specimens had some seminiferous epithelium alterations with small gaps due to cytoplasm shrinkage in some cells. Despite the moderate presence of gaps, intercellular contact was well preserved in most of the tissue specimens, and these gaps were isolated to small spaces within the tubules (Figures 3-6).

\section{DISCUSSION}

This study compared a new vitrification protocol with reduced cryoprotectant exposure to the traditional SPF protocol in the cryopreservation of rat prepubertal testicular tissue. Histology examination revealed that both protocols were capable of adequately preserving the morphological and architectural integrity of the seminiferous tubules.

To minimize possible bias during tissue analysis, all tissue fragments were coded, and the pathologist was blinded to the groups. Very few alterations were observed in fresh tissue specimens; all were related to the tubular epithelium, but tissue integrity was never compromised. The results showed that the steps involved in tissue preparation (surgery, removal of the tunica albuginea, testicular tissue fragmentation, and histological processing) were adequately performed with minimum tissue damage, and that the control group was fit for comparison with the cryopreservation groups.

There is no standardized or universally accepted method to assess the structure of immature testicular cells submitted to tissue cryopreservation protocols. Other authors have analyzed the histology and morphology of testicular tubules stained with hematoxylin-eosin (Baert et al., 2012; Poels et al., 2013). The main limitation of this method is that it cannot definitively evaluate the impact of the procedure on the function of cryopreserved testicular tissue (Kvist et al., 2006). Nonetheless, Milazzo et al. (2008) showed that cell apoptosis was positively associated with the degradation of testicular tissue, i.e., more cell apoptosis was observed in more morphologically deteriorated testicular tissue specimens after different cryopreservation methods. Thus, the small number of morphological alterations found in this study indicates that the testicular tissue specimens were still viable after cryopreservation.

Our results indicate that vitrification was slightly superior to traditional SPF. This finding has been reported in previous studies, indicating that vitrification may eventually become the procedure of choice for the preservation of immature testicular tissue (Curaba et al., 2011; Baert et al., 2012; 2013; Poels et al., 2012; Sá et al., 2012). Over the last decade, different vitrification protocols using different cryoprotectants, concentrations and exposure times, support equipment, as well as testicular tissue preparation time have been used (Curaba et al., 2011; Gouk et al., 2011; Baert et al., 2012; 2013; Poels et al., 2012; Sá et al., 2012; Liu et al., 2013).

In the vitrification protocol used in the present study, the testicular tissue fragments were exposed to cryoprotectants for only $12 \mathrm{~min}$, a $20 \%$ reduction in relation to the fastest $(15 \mathrm{~min}$ ) vitrification protocol described to date (Poels et al., 2012). This reduction in cryoprotectant exposure time may have important implications in cell survival after grafting. Another noteworthy aspect of the protocol described herein concerns the drying of tissue fragments throughout the preparation steps. Drying tissue specimens after immersing them in the first, less concentrated cryoprotectant solution may prevent the dilution of the second, more concentrated solution, thus enhancing its effect. And drying tissue specimens before plunging them into liquid nitrogen may remove excessive cryoprotectant solution, improve tissue preservation, and enhance tissue grafting after thawing.

In this study, the option was made for testicular tissue fragments for the resemblances they carry with clinical reality. Testicular biopsies collected from different areas of the testis of children are always performed in small fragments. The size of the fragments that were cryopreserved was similar to the size of the ones collected from the small size testis of children (Wyns et al., 2008). Moreover, the cryopreservation of testicular fragments is important as the contact between the Sertoli and the germ cells necessary for cell maturation and spermatogenesis is maintained (Ogawa et al., 2005).

One of the technical difficulties met in the execution of the vitrification protocol concerned the handling of testicular tissue. After the tunica albuginea was removed, the remaining testicular tissue was extremely soft. Thus, the testicular tissue specimens were plunged directly into cryovials containing virgin liquid nitrogen. Tissue analysis after thawing did not show significant alterations in tissue morphology, which suggests this might be an appropriate procedure. Nevertheless, further studies may bring innovations concerning testicular tissue handling during vitrification.

Despite the similar results described for both cryopreservation techniques, some points favor the use of vitrification over SPF, particularly the time spent in the procedure. The mean time needed to complete SPF ranged between three to four hours. With vitrification, however, the mean time needed to perform the entire process was only $30 \mathrm{~min}$. As testicular tissue is extremely sensitive, tissue exposure to ischemia may be an important issue in the preservation of cell viability. Moreover, SPF requires a complex and costly apparatus, while the equipment required in vitrification is relatively light and may be easily transported. As there are just a few quick steps to be followed, the vitrification learning curve is significantly less steep than that of SPF. Another important consideration concerns the restricted access to fertility preservation techniques by oncologic patients. Specialist human reproduction services with the SPF equipment required to cryopreserve cells and tissues can only be found in large urban centers, which may either prevent access to the procedure at all or delay the start of cancer treatment. With vitrification, cryopreservation may be performed wherever the patient is, even at a site distant from a frozen tissue bank (Baert et al., 2013).

\section{CONCLUSIONS}

Morphological assessment of the seminiferous tubules revealed that the two analyzed cryopreservation protocols (SPF and vitrification) adequately preserved rat prepubertal testicular tissue. Reduced procedure times and shorter exposure to cryoprotectants may represent a step forward in relation to previous vitrification protocols. However, future studies using the same vitrification protocol are now required to ascertain the reestablishment of cell function after grafting.

\section{ACKNOWLEDGEMENTS}

The authors would like to thank Mr. Antonio Carlos Correa for his support with the English version of the paper, the staff at Materbaby - Human Reproduction for their dedication, and Ingámed (Maringá, Brazil) for kindly supplying the vitrification media used in this experiment.

\section{CONFLICT OF INTERESTS}

The authors have no conflicts of interest to report. 


\section{Corresponding author:}

Moacir Rafael Martins Radaelli

Urology Department, Medical School, Faculdade Ingá,

Maringá, Brazil.

E-mail: rafaradaelli@yahoo.com.br

\section{REFERENCES}

Almodin CG, Minguetti-Camara VC, Paixao CL, Pereira PC. Embryo development and gestation using fresh and vitrified oocytes. Hum Reprod. 2010;25:1192-8. PMID: 20185514 DOI: 10.1093/humrep/deq042

Anserini P, Chiodi S, Spinelli S, Costa M, Conte N, Copello $F$, Bacigalupo A. Semen analysis following allogeneic bone marrow transplantation. Additional data for evidencebased counselling. Bone Marrow Transplant. 2002;30:44751. PMID: 12368957 DOI: $10.1038 /$ sj.bmt. 1703651

Aslam I, Fishel S, Moore H, Dowell K, Thornton S. Fertility preservation of boys undergoing anti-cancer therapy: a review of the existing situation and prospects for the future. Hum Reprod. 2000;15:2154-9. PMID: 11006191 DOI: $10.1093 /$ humrep/15.10.2154

BaertY, Goossens E, van Saen D, Ning L, in't Veld P, TournayeH. Orthotopic grafting of cryopreserved prepubertal testicular tissue: in search of a simple yet effective cryopreservation protocol. Fertil Steril. 2012;97:1152-7.e1-2. PMID: 22369773 DOI: $10.1016 /$ j.fertnstert.2012.02.010

Baert $Y$, Van Saen D, Haentjens $P$, In't Veld $P$, Tournaye $\mathrm{H}$, Goossens E. What is the best cryopreservation protocol for human testicular tissue banking? Hum Reprod. 2013;28:1816-26. PMID: 23569082 DOI: $10.1093 /$ humrep/det100

Blatt J. Pregnancy outcome in long-term survivors of childhood cancer. Med Ped Oncol. 1999;33:2933. PMID: 10401494 DOI: $10.1002 /(\mathrm{SICI}) 1096-$ 911X(199907)33:1<29::AID-MPO6>3.0.CO;2-2

Bleyer WA. The impact of childhood cancer on the United States and the world. CA Cancer J Clin. 1990;40:355-67. PMID: 2121321 DOI: 10.3322/canjclin.40.6.355

Brenner $H$, Steliarova-Foucher $E$, Arndt V. Up-to-date monitoring of childhood cancer long-term survival in Europe: methodology and application to all forms of cancer combined. Ann Oncol. 2007;18:1561-8. PMID: 17660498 DOI: $10.1093 / a n n o n c / m d m 186$

Brougham MF, Kelnar CJ, Sharpe RM, Wallace WH. Male fertility following childhood cancer: current concepts and future therapies. Asian J Androl. 2003;5:325-37. PMID: 14695983

Curaba $M$, Verleysen $M$, Amorim CA, Dolmans $M M$, Van Langendonckt A, Hovatta O, Wyns C, Donnez J. Cryopreservation of prepubertal mouse testicular tissue by vitrification. Fertil Steril. 2011a;95:1229-34.e1. PMID: 20541745 DOI: $10.1016 /$ j.fertnstert.2010.04.062

Curaba M, Poels J, van Langendonckt A, Donnez J, Wyns C. Can prepubertal human testicular tissue be cryopreserved by vitrification? Fertil Steril. 2011b;95:2123.e9-12. PMID: 21300331 DOI: 10.1016/j.fertnstert.2011.01.014
Di Santo M, Tarozzi N, Nadalini M, Borini A. Human Sperm Cryopreservation: Update on Techniques, Effect on DNA Integrity, and Implications for ART. Adv Urol. 2012;2012:854837. PMID: 22194740 DOI: $10.1155 / 2012 / 854837$

Gouk SS, Loh YF, Kumar SD, Watson PF, Kuleshova LL. Cryopreservation of mouse testicular tissue: prospect for harvesting spermatogonial stem cells for fertility preservation. Fertil Steril. 2011;95:2399-403. PMID: 21481372 DOI: $10.1016 / j$.fertnstert.2011.03.035

Howell S, Shalet S. Gonadal damage from chemotherapy and radiotherapy. Endocrinol Metab Clin North Am. 1998;27:927-43. PMID: 9922915 DOI: $10.1016 /$ S0889-8529(05)70048-7

Keros V, Rosenlund B, Hultenby K, Aghajanova L, Levkov $L$, Hovatta O. Optimizing cryopreservation of human testicular tissue: comparison of protocols with glycerol, propanediol and dimethylsulphoxide as cryoprotectants. Hum Reprod. 2005;20:1676-87. PMID: 15860503 DOI: 10.1093/humrep/deh797

Kvist K, Thorup J, Byskov AG, Høyer PE, Møllgård K, Yding Andersen C. Cryopreservation of intact testicular tissue from boys with cryptorchidism. Hum Reprod. 2006;21:48491. PMID: 16210383 DOI: 10.1093/humrep/dei331

Levine J, Canada A, Stern CJ. Fertility preservation in adolescents and young adults with cancer. J Clin Oncol. 2010;28:4831-41. PMID: 20458029 DOI: 10.1200/JCO.2009.22.8312

Liu J, Cheng KM, Silversides FG. Production of live offspring from testicular tissue cryopreserved by vitrification procedures in Japanese quail (Coturnix japonica). Biol Reprod. 2013;88:124. PMID: 23575148 DOI: $10.1095 /$ biolreprod.113.108951

Magnani C, Pastore G, Coebergh JW, Viscomi S, Spix C, Steliarova-Foucher E. Trends in survival after childhood cancer in Europe, 1978-1997: report from the Automated Childhood Cancer Information System project (ACCIS). Eur J Cancer. 2006;42:1981-2005. PMID: 16919766 DOI: 10.1016/j.ejca.2006.05.006

Milazzo JP, Vaudreuil L, Cauliez B, Gruel E, Massé L, Mousset-Siméon N, Macé $B$, Rives N. Comparison of conditions for cryopreservation of testicular tissue from immature mice. Hum Reprod. 2008;23:17-28. PMID: 17989070 DOI: $10.1093 /$ humrep/dem355

Neri QV, Feliciano M, Tanaka N, Palermo L, Schlegel PN, Palermo GD. Vitrification of testicular tissue is more gentle on germ cells. Fertil Steril. 2004;82:S184. DOI: $10.1016 /$ j.fertnstert.2004.07.483

Ogawa T, Ohmura M, Ohbo $K$. The niche for spermatogonial stem cells in the mammalian testis. Int J Hematol. 2005;82:381-8. PMID: 16533739 DOI: $10.1532 / \mathrm{IJH} 97.05088$

Poels J, Van Langendonckt A, Dehoux JP, Donnez J, Wyns C. Vitrification of non-human primate immature testicular tissue allows maintenance of proliferating spermatogonial cells after xenografting to recipient mice. Theriogenology. 2012;77:1008-13. PMID: 22153273 DOI: $10.1016 /$ j.theriogenology.2011.10.015 
Poels J, Van Langendonckt A, Many MC, Wese FX, Wyns C. Vitrification preserves proliferation capacity in human spermatogonia. Hum Reprod. 2013;28:578-89. PMID: 23315062 DOI: $10.1093 /$ humrep/des455

Ries LAG, Eisner MP, Kosary CL, Hankey BF, Miller $B A$, Clegg L, Mariotto A, Feuer EJ, Edwards BK, eds. SEER Cancer Statistics Review, 1975-2001, National Cancer Institute. Bethesda; 2004. Available at: https://seer.cancer.gov/archive/csr/1975_2001/. Accessed: 23/07/2011.

Romerius $\mathrm{P}$, Ståhl $\mathrm{O}$, Moëll $\mathrm{C}$, Relander T, Cavallin-Ståhl E, Wiebe T, Giwercman YL, Giwercman A. High risk of azoospermia in men treated for childhood cancer. Int J Androl. 2011;34:69-76. PMID: 20345878 DOI: 10.1111/j.1365-2605.2010.01058.x

Sá R, Cremades N, Malheiro I, Sousa M. Cryopreservation of human testicular diploid germ cell suspensions. Andrologia. 2012;44:366-72. PMID: 22420610 DOI: $10.1111 / \mathrm{j} .1439-0272.2012 .01290 . x$

Schrader M, Müller M, Straub B, Miller K. The impact of chemotherapy on male fertility: a survey of the biologic basis and clinical aspects. Reprod Toxicol. 2001;15:611-7. PMID: 11738514 DOI: 10.1016/S0890-6238(01)00182-4

Steliarova-FoucherE, Stiller C, Kaatsch P, Berrino F, Coebergh JW, Lacour B, Parkin M. Geographical patterns and time trends of cancer incidence and survival among children and adolescents in Europe since the 1970s (the ACCISproject): an epidemiological study. Lancet. 2004;364:2097-105. PMID: 15589307 DOI: 10.1016/S0140-6736(04)17550-8
Stiller CA, Desandes E, Danon SE, Izarzugaza I, Ratiu A, Vassileva-Valerianova Z, Steliarova-Foucher E. Cancer incidence and survival in European adolescents (19781997). Report from the Automated Childhood Cancer Information System project. Eur J Cancer. 2006;42:200618. PMID: 16919767 DOI: 10.1016/j.ejca.2006.06.002

Trottmann M, Becker AJ, Stadler T, Straub J, Soljanik I, Schlenker B, Stief CG. Semen quality in men with malignant diseases before and after therapy and the role of cryopreservation. Eur Urol. 2007;52:355-67. PMID: 17498866 DOI: $10.1016 /$ j.eururo.2007.03.085

Wallace WH, Anderson RA, Irvine DS. Fertility preservation for young patients with cancer: who is at risk and what can be offered? Lancet Oncol. 2005;6:209-18. PMID: 15811616 DOI: $10.1016 /$ S1470-2045(05)70092-9

Wyns C, Curaba M, Martinez-Madrid B, Van Langendonckt A, François-Xavier W, Donnez J. Spermatogonial survival after cryopreservation and short-term orthotopic immature human cryptorchid testicular tissue grafting to immunodeficient mice. Hum Reprod. 2007;22:1603-11. PMID: 17483089 DOI: 10.1093/humrep/dem062

Wyns C, Van Langendonckt A, Wese FX, Donnez J, Curaba M. Long-term spermatogonial survival in cryopreserved and xenografted immature human testicular tissue. Hum Reprod. 2008;23:2402-14. PMID: 18664476 DOI: 10.1093/humrep/den272 